\title{
Investigations on Nonlinear Tito System using Passivity Based Control in Real Time
}

\author{
Priya $C^{*}$, Lakshmi Ponnnusamy\#, Ramya $S^{\$}$, Aparna $S^{@}$, Rajeshwari $M^{\&}$ \\ *Assistant Professor, ${ }^{\$ @ \& ~ U G ~ S t u d e n t s ; ~ D e p a r t m e n t ~ o f ~ E l e c t r o n i c s ~ a n d ~ I n s t r u m e n t a t i o n ~ E n g i n e e r i n g, ~}$ \\ Sri SaiRam Engineering College, Chennai, India \\ \#Professor, Department of Electrical and Electronics Engineering, College of Engineering, Anna \\ University, Chennai, India
}

(Received 29 August 2019: accepted 30 December, 2019)

https://doi.org/10.36224/ijes.120402

\begin{abstract}
The concept of passivity for nonlinear systems attracted new interest in nonlinear system control. This work aims to develop a control algorithm using Passivity Based Control (PBC) for a Two Input Two Output (TITO) system namely spherical-conical interacting coupled tank system in real time. Conical tank spherical tank combination together with the interaction makes the system highly nonlinear system. Real time model of the SISO and TITO systems are obtained experimentally by black box modeling. A computer based control system is developed and the process data is obtained using USB based VUDAS-100 data acquisition module. The algorithm for control is developed in the PC with conventional PI controller and also with PBC and the controller performance is compared. The robustness of the controllers is validated by imposing both servo and regulatory operations. Both the SISO and TITO system results obtained in real time shows that PBC works efficiently with improved performance compared to ZN based PI controller.
\end{abstract}

Keywords: Two Input Two Output system, passivity based controller, spherical-conical interacting system, conical tank system, PI Controller

\section{Introduction}

Conical tank and spherical tank systems are variable area Single Input Single Output (SISO) nonlinear systems. The combination of two nonlinear systems makes it a Two Input Two Output (TITO) system, together with the interaction between the systems and the presence of dead time makes this a challenging problem in real time and so there is a need to use new control technique. Works on level control of nonlinear systems namely Spherical Conical Interacting Tank System (SCITS) [1], conical tank system [2], spherical tank system [3,4], Two Tank Conical Interacting System (TTCIS) [5] and Two Tank Spherical Interacting System (TTSIS) [6] and their applications are discussed.

The level control becomes difficult due to the nonlinear shape of tank that is the rate of rise of water in the narrow part is high and gets reduced as height increases in the case of conical tank whereas in the case of spherical tank the rate of rise of water in the bottom part is high becomes slow in the middle portion and again becomes high in the top portion of the tank thus causing non linear rise in level in both the cases.

The most popular controller Proportional Integral/Proportional Integral Derivative (PI/PID) controller has simple tuning rules based on minimum plant model knowledge [7] but it lacks the intelligence and flexibility which would increase the performance rate and 
also improve the stability and error criterion $[8,9]$. Intelligent control techniques like neural network and fuzzy logic mimic the functioning of the human intelligence process but their real time implementation is tedious [10]. Fuzzy logic controller tuning also depends on the human expertise.

This paper attempts to give practical advantage of Passivity Based Controller (PBCr) over conventional PI controller for TITO system involving level control in real time. The passivity theory plays an important role in designing controller for nonlinear systems. Lot of research works are reported on the passivity method for different applications [11]. The PBCr for nonlinear control is discussed in [12] and particularly for nonlinear chemical process control are dealt in [13-15].

This paper is organized as follows. Experimental setup and system identification is given in section 2. The design of conventional PI controller and PBC is discussed in section 3. TITO system real time results are discussed in section 4. Finally section 5 concludes the paper.

\section{Experimental setup and system identification}

The experimental setup of the SCITS is shown in Figure 1 and discussed in detail [1]. The objective is to control the level of the TITO system both the spherical tank level $\mathrm{h}_{1}$ and conical tank system level $h_{2}$ are controlled. Thus level is the controlled variable. Level is maintained by varying the inflow to the tank which is obtained by the control valve stem position adjustment. Thus inflow to the tank is the manipulated variable.

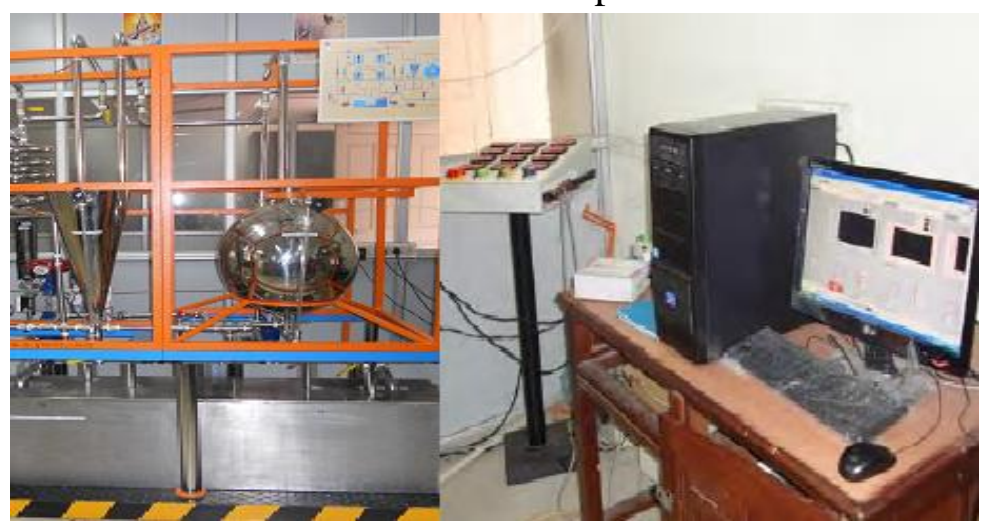

Figure 1: Experimental Setup of SCITS

\subsection{MIMO - Spherical Conical Interacting Tank System (SCITS)}

The transfer function matrix of a SCITS for the operating point of $\mathrm{h}_{1}=17 \mathrm{~cm}$ and $\mathrm{h}_{2}=15 \mathrm{~cm}$ is represented as below [1]

$$
\left[\begin{array}{l}
h_{1}(s) \\
h_{2}(s)
\end{array}\right]=\left[\begin{array}{ll}
\frac{0.9}{1935 s+1} e^{535} & \frac{1.85}{1380 s+1} e^{380 s} \\
\frac{0.4}{1350 s+1} e^{350 s} & \frac{2.3}{1590 s+1} e^{440 s}
\end{array}\right]\left[\begin{array}{l}
u_{1}(s) \\
u_{2}(s)
\end{array}\right]
$$


where $h_{1}$ and $h_{2}$ are the outputs, which are water level in the spherical and conical tank, $\mathrm{u}_{1}$ and $\mathrm{u}_{2}$ are the input flow to the spherical and conical tank. From the Relative Gain Array (RGA) analysis pairing is decided to be $\mathrm{u}_{1}-\mathrm{h}_{1}$ and $\mathrm{u}_{2}-\mathrm{h}_{2}$.

\section{Controller design}

The PI tuning parameters for Zeigler Nichols [8] method are $\mathrm{Kp}=2.010$ and $\mathrm{Ti}=127.396$ for SISO conical tank system and $\mathrm{Kc11}=2.835$, Ti11=1689 for $\mathrm{GC} 1$ and $\mathrm{KC} 22=1.3$ and Ti22=1509 for GC2 for MIMO spherical conical interacting system where Gc1and Gc2 are decentralized PI controllers.

The PBC equations are discussed in detail in [1] and the final controller expression is restated as

$$
\left\{\begin{array}{c}
U=\frac{1}{C}\left[-D\left(x_{1}-x_{1 d}\right)-R_{2} \int\left(x_{1}-x_{1 d}\right) d t-R_{2}\left(x_{2}-\overline{x_{2}}\right)\right]+\bar{u} \\
x_{1 d}^{*}=-\left(D+\frac{A}{x_{1}}\right) x_{1 d}+D \overline{x_{2}}+R_{1}\left(x_{1}-x_{1 d}\right)
\end{array}\right.
$$

The parameters A, C and D are calculated from the system model [1] and the other PBC parameters are set $\mathrm{R} 1=0.15, \mathrm{R} 2=0.12, \mathrm{R} 3=0.005, \overline{x_{2}}=3$ for $\mathrm{Gc} 1$ and $\mathrm{R} 1=0.15, \mathrm{R} 2=$ $0.15, \mathrm{R} 3=0.009$ and $\overline{x_{2}}=1$ for Gc2 in the case of TITO spherical conical interacting system.

\section{Experimental results and discussion}

The controllers are implemented in real time for the SISO and TITO process and their performances are discussed.

\subsection{TITO - Spherical conical interacting tank system (SCITS)}

The real time servo response is obtained for TITO process similar to SISO process and the comparison of both the controller for tank 1 (spherical tank) and tank 2 (conical tank) are shown in Figure 2a and b. Regulatory response comparison is shown in Figure 3 to Figure 5 for ZN/PI controller and PBCr. Regulatory response are obtained in two different ways. Disturbance given in one tank will affect the other tank due to interaction present between the tanks. Firstly disturbance is given to the spherical tank (Tank 1) and the effect of disturbance is noted in the spherical tank (Figure 3a) as well as in the conical tank (Figure 3b). Secondly disturbance is applied to the conical tank and effect of disturbance is noted in conical tank (Figure 4) and spherical tank (Figure 5). 5Litres of water is added to the spherical tank as disturbance due to its large area and 2 Litres of water is added to the conical tank as disturbance due to comparatively lesser area.

This 5 Litres of water added to the spherical tank will also increase the water level in the conical tank due to interaction present between the tanks. Similarly 2 litres of water added to the conical tank will also increase the water level in the spherical tank due to the effect of interaction. Performance analysis of servo response and regulatory response of TITO process for level h1 and h2 is given in Table 1, 2, and 3 with normalized ISE and ITAE values. 


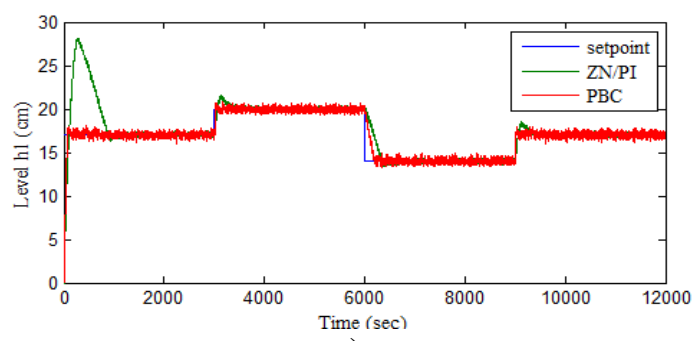

a)

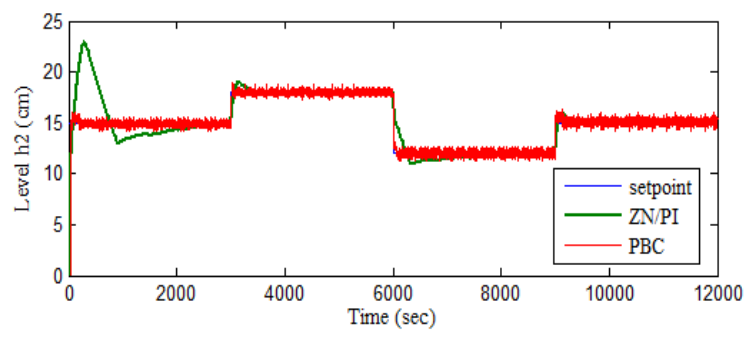

b)

Figure 2: Servo response comparison of ZN/PI controller and PBC for level in a)Tank 1 (h1) and b) Tank 2 of TITO process.

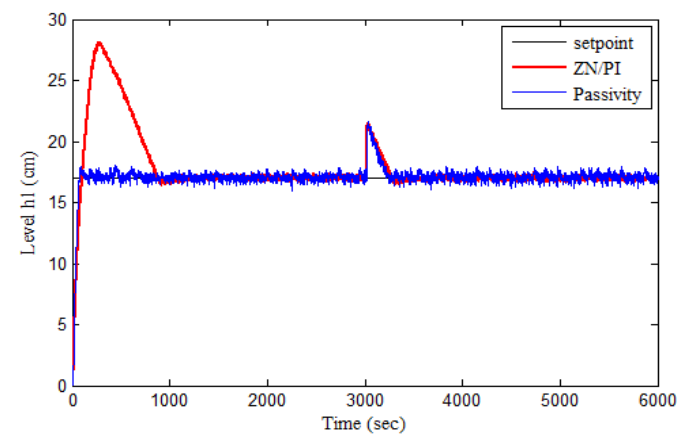

a)

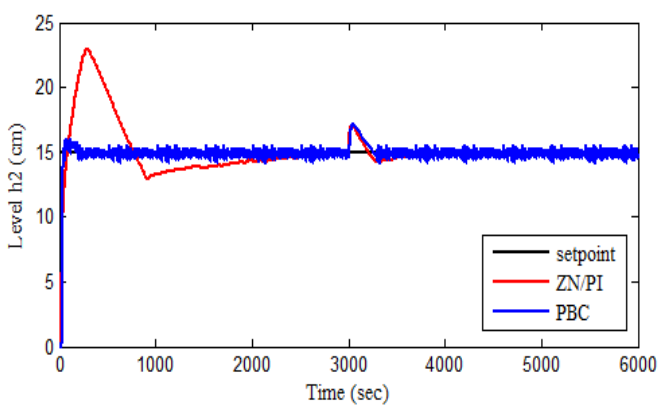

b)

Figure 3: a) Regulatory response comparison of ZN/PI controller and PBC obtained by adding 5L of water to the spherical tank (h1) and b): The corresponding increase in water level in the conical tank h2 due to interaction present.

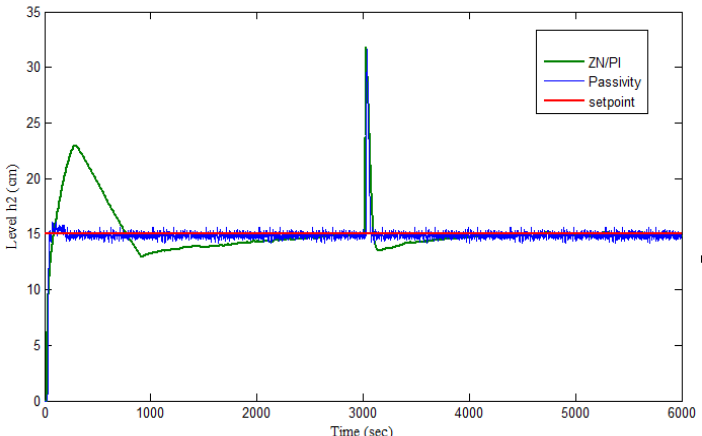

a)

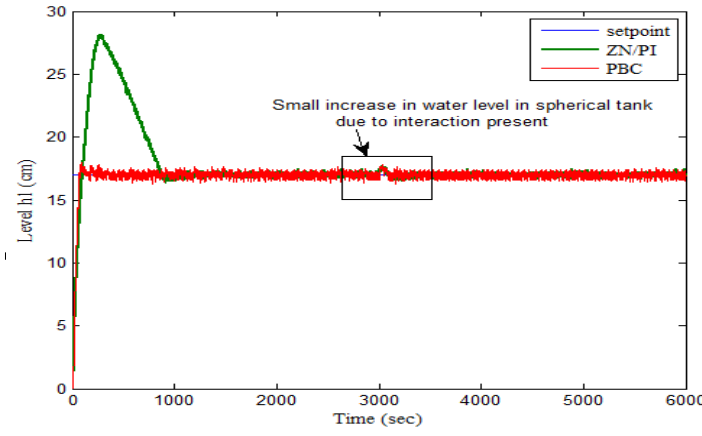

b)

Figure 4: a)Regulatory response comparison of ZN/PI controller and PBC obtained by adding 2L of water to the conical tank (h2) and b) The corresponding increase in water level in the spherical tank h1 due to interaction present.

Table 1: Performance analysis of servo response of level h1 and h2 of TITO system in real time

\begin{tabular}{|l|c|c|c|c|}
\hline \multirow{2}{*}{ Type of controller } & \multicolumn{3}{|c|}{ Servo Response } \\
\cline { 2 - 5 } & Level output of tank 1 (h1) & \multicolumn{2}{|c|}{ Level output of tank 2 (h2) } \\
\cline { 2 - 5 } & ISE & ITAE & ISE & ITAE \\
\hline ZN/ PI & 42.49 & 14916.67 & 21.93 & 14916.67 \\
\hline Passivity based control & 6.56 & 14666.67 & 0.296 & 12166.67 \\
\hline
\end{tabular}


Table 2: Performance analysis of Regulatory response of level h1 of TITO system in real time

\begin{tabular}{|l|l|l|l|l|}
\hline \multirow{2}{*}{ Type of controller } & \multicolumn{4}{|l|}{ Regulatory Response-Effect of adding 5L of water in tank 1 } \\
\cline { 2 - 5 } & $\mathrm{h} 1$ & \multicolumn{2}{|l|}{ Effect in h2 } \\
\cline { 2 - 5 } & ISE & ITAE & ISE & ITAE \\
\hline ZN/ PI & 78.9 & 8817.35 & 39.96 & 10781.49 \\
\hline Passivity based control & 10.4 & 7127.62 & 5.44 & 5570.77 \\
\hline
\end{tabular}

Table 3: Performance analysis of Regulatory response of level h2 of TITO system in real time

\begin{tabular}{|l|l|l|l|l|}
\hline \multicolumn{1}{|c|}{ Type of controller } & \multicolumn{4}{|c|}{ Regulatory Response-Effect of adding 2L of water in tank 2 } \\
\hline & \multicolumn{2}{|c|}{ h2 } & \multicolumn{2}{|c|}{ Effect in h1 } \\
\hline & ISE & ITAE & ISE & ITAE \\
\hline ZN/ PI & 53.11 & 15199.5 & 76.06 & 5982.98 \\
\hline Passivity based control & 10.81 & 6024.27 & 8.33 & 4068.47 \\
\hline
\end{tabular}

In TITO SCITS percentage overshoot and the settling time has been decreased for both the tank level h1 and h2 by using PBCr which is evident from the servo and regulatory response in Figure 4 through 7. The ISE and ITAE values from Table 1 to 3 are also observed to be very less by using PBCr compared to $\mathrm{ZN}$ tuned PI controller.

\section{Conclusions}

In this work PBCr is used for the level control of a new combination of spherical conical interacting tank system in order to demonstrate its applicability for variable area nonlinear TITO systems in real time. The proposed passivity based controller equation is simple and the tuning parameters are obtained from the FOPDT model of the system. Better servo and regulatory responses are obtained for both the systems with passivity based controller, comparatively to those obtained with $\mathrm{ZN}$ tuned PI controller. The $\mathrm{PBCr}$ has reduced the overshoot, settling time and also the performance criterion is always less for the passivity based controller compared to $\mathrm{ZN}$ based PI controller for both the systems. The real time results show the effectiveness of PBC over ZN/PI controller.

\section{References}

1. Priya Chandrasekar and Lakshmi Ponnusamy, Comparative study of controllers for a variable Area MIMO interacting nonlinear system, International Journal of Engineering and Technology, 2014,6(1) 227-235

2. Giriraj Kumar, S.M., Sivasankar, R., Radhakrishnan, T.K., Dharmalingam, V and Anantharaman, N., Particle swarm optimization Technique based design of PI controller for a real-time nonlinear process, Instrumentation Science and Technology,2008, 36(5) 525-542

3. Nithya, S., Sivakumaran, N., Balasubramanian, T and Anantharaman, N., Model based controller design for spherical tank process is real in real time, IJSSST,2008, 9(4) 25-31

4. Giriraj Kumar, S.M., Sivasankar, R., Radhakrishnan, T.K., Dharmalingam, V and Anantharaman, N., Genetic Algorithms for level control in a real time process, Sensors \& Transducers Journal,2008, 97(10), 22-33

5. V. R. Ravi and T. Thyagarajan, A decentralized PID controller for interacting nonlinear systems, Proceedings of ICETECT 2008, 297-302 
6. Dinesh Kumar, D., Dinesh, C. and Gautham, S., Design and implementation of Skogestad PID controller for interacting spherical tank system, International Journal of Advanced Electrical and Electronics Engineering, 2008, 2(4)117-120

7. Ziegler, J. G., Nichols, N.B., Optimum Settings For Automatic Controllers, Trans. Amer. Soc.Mech. Eng., 64(8),759-768

8. Su Whan Sung, In-Beum Lee and Jitae Lee, Modified Proportional-Integral Derivative (PID) Controller and a New Tuning Method for the PID Controller, Ind. Eng. Chem. Res.,1995,34(11), 4127-4132

9. Mehrdad Salami and Greg Cain, An adaptive PID controller based on Genetic Algorithm processor, Genetic Algorithms in engineering systems: Innovations and applications, IEEE, Conference, September 1995, 88-93

10.Simon Fabri and Visakan Kadirkamanathan, "Dynamic structure neural networks for stable adaptive control of nonlinear systems, IEEE Transactions on Neural Networks, September,1996, 7(5), 1151-1167

11. Ortega, R., Loria, A., Nicklarron, P.J., Sira-Ramirez, H., Passivity-based control of EulerLagrange Systems: Mechanical, Electrical and Electromechanical Applications, Communications and Control Engineering Series Springer: Berlin, 1998

12.Batle, C., Doria-Cerezo, A., Espinosa-Perez, G., Ortega, R., Simultaneous Interconnection and Damping Assignment Passivity-Based Control: Two Practical Examples, 3rd IFAC Workshop on Lagrangian and Hamiltonian Methods for Nonlinear Control, Nogoya, 2006, 93-98

13.Sira, H., Angulo, M., Passivity-based control of Nonlinear Chemical Processes, International Journal of Control,1997, 68(5), 971-996

14.Sira, H., A General Canonical Form for feedback Passivity of nonlinear Systems, International Journal of Control,1998, 71(5) 891-905

15. Oscar Chamaco, Ruben Rojas, Alpha Pernia-Espinoza and Mercedes Perez de la Parte, Passivitybased controller for chemical processes, Rev. Tech. Ing. Univ. Zulia.2002, 25,(1), 3-11 